\title{
Exploring the Rendition of Humor in Dubbed English Comedy Animations into Persian
}

\author{
Hamid Reza Sadeghpour \\ Department of English, Ferdowsi University of Mashhad, Iran \\ E-mail: hamidrezasadeghpour@gmail.com \\ Ali Khazaeefar \\ Department of English, Ferdowsi University of Mashhad, Iran \\ Masood Khoshsaligheh \\ Department of English, Ferdowsi University of Mashhad, Iran
}

Received: 28-03- 2015

Published: 01-11- 2015
Accepted: 23-06- 2015

doi:10.7575/aiac.ijalel.v.4n.6p.69
Advance Access Published: August 2015

URL: http://dx.doi.org/10.7575/aiac.ijalel.v.4n.6p.69

\begin{abstract}
Dubbing is one of the developing areas in Translation Studies, and this study aimed at investigating the translation strategies used in the dubbing of comedy animations from English to Persian. Since colloquial, idiomatic, and humorous expressions have the capacity to elicit laughter and as it is not always easy to draw a clear-cut line between these three types of expressions, this study examines all three types, investigating the strategies used in translating these expressions. The data was collected from five popular American comedy animations dubbed into Persian. The original humorous, colloquial, and idiomatic expressions and their Persian translations were written down and the strategies used in translating them were identified and classified into nine groups for further analysis. The findings from the sample demonstrate that the Persian translators tend to use familiar expressions rather than translate literally and that beside humorous expressions, the translators tend to use idiomatic and colloquial expressions to produce laughter mostly in cases where the original animation has not used them. In short, the Persian translators have frequently and freely used idiomatic and colloquial expressions in their secondary function to elicit laughter which is a strategy that can be used in the translation of comedies, especially for children, where there are numerous linguistic and cultural barriers across the cultures.
\end{abstract}

Keywords: Audiovisual translation, Dubbing, Idiom, Colloquial expressions, Persian

\section{Introduction}

By the 1980s, translation studies became an independent discipline, and translation scholars began to do research in various areas of this newly established discipline. Translation is vaguely divided to oral, commonly known as interpreting, and written translation. According to Munday (2008:5) the term translation has a number of meanings: it can refer to the general subject field, the product (the text that has been translated) or the process (the act of producing the translation, also known as translating). Translation studies is an interdisciplinary research area; hence, investigators from a wide range of disciplines have done numerous studies in this regard. Many areas in translation studies still need more investigation. One of these areas which require more attention and research is humor translation. Humor is a universal concept and can be traced and noticed in all the languages and cultures. Humor translation is a very complicated process due to linguistic, paralinguistic and cultural variations across languages and cultures. The field of humor translation has been discussed extensively by linguists, some of whom addressing the untranslatability issues and some seeking innovative methods to achieve their purpose. Even so, Vandaele (2002) believed that humor translation was not widely investigated on an academic basic, and that it was dealt with by a limited number of practitioners (p.151). The difficulty of humor translation is not merely a matter of individual words. If audiences are not familiar with source culture, although the words carry meaning, the likelihood of misunderstanding is still high. In order to transfer humorous expressions properly, translators should have in-depth background knowledge of source and target culture. There are numerous strategies that translators apply to transfer the humorous expressions from source text to target text and has proved to be a formidable challenge, as Maher (2008, cited in Akmali, 2012:141) puts it "the translation of humor is a notoriously difficult endeavor, not least because of the close links between humor and identity and between humor and culture". Translators in Iran have to cope with an awful lot of problems translating humorous expressions. They use as many strategies as possible to convey the humorous expressions in Persian and simultaneously to domesticate them for the Iranian audience. Many elements of humor must be excluded since they are considered taboo in the Iranian culture and; therefore, the task of translators to maintain the cohesion of the movie is very difficult. 
In recent decades new forms of media have been devised and expanded, and evidently the most influential and widely used form of media is television. The complication of messages in audiovisual products results from the combination of linguistic and metalinguistic elements. Therefore, audiovisual translation poses a new challenge for translators. Additionally, this new branch of translation studies coincides with the development of film industry, dubbing and subtitling. The concern of this study is the dubbing of American comedy animations from English into Persian. The study is not aiming at the counterpart, subtitling, as it is not officially practiced in Iran, and they are basically reduced to fansubs. This study was conducted through investigating different strategies applied by AV translators, such as using various accents and jargons in dubbing to change non-colloquial sentences to colloquial ones or vice versa. Another method can be translating idioms to idioms. Additionally, a number of other techniques can be manipulating, paraphrasing, deletion and even changing a non-humorous phrase or clause to a humorous one in accordance to the context. The present study is an exploratory investigation which aims to obtain insight into how American comedy animation is handled when dubbed into Persian, with all the discrepancies of the Persian culture and locale with that of the source side.

\section{Literature Review}

\subsection{Audiovisual Translation}

Translation studies is a broad interdisciplinary field as it can be divided into twelve research areas among which, there is the area of Audiovisual Translation (AVT) in which Dubbing and Subtitling are inserted (Williams \& Chesterman, 2002:44). Research on this realm started in the late 1950 s and flourished in late $20^{\text {th }}$ century. The first studies on AVT were published in newspapers and journals of translation irregularly and there is no access to them today. The first official book on AVT is called subtitling of movie written by Laks in 1957. The first conference on Subtitling and Dubbing were held in Stockholm in 1987. This was a motivation for publishing many books and articles on this subject. Delabastita $(1989,1990)$ was beyond doubt the first scholar who described semiotic of audiovisual products from a descriptive perspective. His study focused more on cultural perspectives. He analyzed translation as a process and posed questions which still guide the curious mind of audiovisual investigators. In 1989 Lambert published a similar work in France which discussed the power of media in society and the role of language and translation. In fact he introduced a new view point to show how ideological forces influence audiovisual products. Scholars gave many definitions for audiovisual translation, for instance Chiaro (2009b) defines audiovisual translation (AVT) as follows:

Audiovisual translation is one of the several umbrella terms that include 'media translation', 'multimedia translation', multimodal translation' and 'screen translation'. These different terms all set out to cover the interlingual transfer of verbal language when it is transmitted and accessed both visually and acoustically, usually but not necessarily, through some kind of electronic device. (p. 141)

\subsection{Dubbing Process}

Translation for the purpose of dubbing is one of the most important areas within the field of translation. Luyken et al (1991:12) defined dubbing as a practice which involves "the replacement of the original speech by a voice track which attempts to follow as closely as possible the timing, phrasing and lip-movements of the original dialogue". People who watched the original and dubbed versions of a movie and were familiar with the original language confirm that numerous differences abide between them. In dubbing not only the voices are different but also the translated text needs to go through some changes in order to be compatible with the target culture. Furthermore, many changes are required for the sake of synchronization in dubbing. A translator's work is the initial point for the long and complicated process of dubbing which are more or less in respect of the original source. Audiovisual translation consists of various parts which have to be done in order and if a problem occurs in every section, there would be unwanted effects on other parts. Orero (2004) states that "the translator's work is often not the final product but a sort of draft version which is polished and adjusted to the needs and demands of the medium" (p. 7). In fact the work starts with translators but there are several steps to the end which are closely linked together and should be done in order. Dubbing is more expensive and time consuming than subtitling and many people are involved in the process.

\subsection{Humor Translation Strategies}

Humor is very important in our society today and several attempts have been made to define its meaning by scholars. For example, Ross (1998) defines humor as something that makes a person laugh or smile (p.1). Due to the globalization of media, the transfer of meaning between cultures is inevitable. And the realm of humor is not an exception. Many find humor translation difficult because of the challenges translators face while doing the process. Needless to mention, translators should first recognize the humor and then transfer it.

The first problem is the linguistic issues which include differences in lexicons, grammars, wordplays and expressions. In wordplays, error of lexicon, change, creation, ambiguity and play on the meanings are done too frequently and in fact it amuses the listener by breaking the standard rules which are not expected. Humor expressions are completely dependent on the source language structure. There are some words in every language which have the same writing form but have different meanings; they are called homographs. These wordplays are not translatable to other language all the time because it may be possible that a lexical item has several meanings in a certain language but only one meaning in another language. In fact the chances that two lexical items have the same meanings in different languages are slim. Therefore, it is difficult to find equivalences for this kind of wordplays; and literal translation is not a good option since the meaning will be distorted. Even if we substitute a linguistic humor with another one, the structure and meaning will 
change. We cannot ignore linguistic humor because it has an important role in the creation and formation of humor. However; translators should either retain the wordplays or omit them. These are great challenges for translators. Translators not only must have complete knowledge of the two languages but also need creativity.

Professional translators use many strategies to ensure a successful end product. As the aim of the study is to investigate translation strategies of the dubbed version of comedy animations, discussing translation strategies for screen translation is greatly required. Gottlieb (1997c) has created a taxonomy of strategies in relation to the screen translation. Most of the strategies can be used for other types of translation but some are developed specifically for one method, for example: condensation strategy is specifically used for subtitling. Gottlieb's (1997c) taxonomy is as follows:

1) Expansion

Using the expansion strategy means making the message of the ST clearer to the receivers of the TT, while it remains an adequate translation. This strategy is often applied in relation to culture-specific elements. Expansion strategy is not media -specific. Expansion strategy may create problems in screen translations, as limitations in space in subtitling and lip-sync in dubbing must be noticed.

\section{2) Paraphrase}

Paraphrase is used when an expression is not translatable. This means the translator uses an expression which in the TL has the same meaning as the SL-expression. Paraphrasing is useful when one is dealing with idioms. This strategy is not specific to screen translation.

3) Transfer

This strategy is used when the content of the ST is uncomplicated and the dialogue is slow allowing the translator to translate everything.

4) Imitation

When an expression in the ST can be translated/transferred with an identical expression the imitation strategy is used. Examples of this are names of people and places. He calls this, identical expression with an equivalence rendering.

5) Transcription

This strategy is a media-specific translation type as it is mostly used in subtitling. This strategy is used when translators come across anomalous expressions. Transcription is also used to indicate dialects and non-standard speech and is a result of the transition from spoken verbal language to written verbal language.

6) Dislocation

Dislocation is specific to subtitling and is employed when dealing with musical or visualized language-specific phenomena. The translator has to be as loyal as possible to the audiovisual communicative channel.

7) Condensation

Occasionally the translator has to make use of the condensation strategy. This strategy can be a consequence of the reading ability of the receiver as well as caused by the limitations of the medium. Condensation is a shortened expression with an adequate content.

8) Decimation

If the speed of the dialogue is too fast to reproduce and the content is of some importance the translator has to resort to the strategy of decimation. This results in reduces content and an abridged expression in the TT.

9) Deletion

If the speed of the dialogue is too fast to reproduce and the content is of less importance the translator has the option of deletion.

10) Resignation

The concept of resignation occurs when the translation is made by means of a parallel expression with differing concept compared to the original dialogue (Gottlieb, 1997c:75).

Another problem is that something which may be considered humorous in a specific culture might not be humorous in another culture. In this respect Ross (1998) states that a certain joke can be found tremendously funny in one context and not result in laughter or even a smile in another (p.1). People may laugh at something in a specific culture which is not funny in another one. The reason is that people understand the world differently. Moreover, people share some cultural elements within the same community that other cultures are not familiar with them. Therefore, familiarity of the source language and culture is crucial in understanding the jokes.

\subsection{Idioms}

Idioms are one of the most challenging aspects in translation and translators need approximately perfect background knowledge about the source and target cultures and languages in order to first recognize them in texts and then find proper idioms in the target text. Idioms are non-changeable words that stick together and form a new meaning which normally differs from the literal meaning of its words. Langaker (1968) suggest that an idiom is a kind of complex lexical item. It is a phrase whose meaning cannot be predicted from the meaning of the morphemes it comprises (p.47). 
Through history words have significantly changed; many words lost their meaning and got new ones but idioms hardly ever changed. Idioms are used in a wide variety of situations from formal to informal and oral to written textures. Many scholars define idioms and some of them are mentioned here for better understanding of the concept of idioms. Baker (1992) argues that idioms are frozen patterns of language, which allow little or no variation in form and often carry meanings which cannot be deduced from their individual components (p.63). She also counts five conditions for idioms as follows:

1. The order of the words in an idiom cannot be changed. The way the words are put together is fixed and they cannot change their place, e.g. "go to rack and ruin" not "go to ruin and rack".

2. The words in an idiom cannot be omitted. We as the users of the language are not permitted to delete some of the words of a particular element, e.g. "shed crocodile tears" and not "shed tears".

3. There are no extra words that might be added to an idiom, e.g. "have a narrow escape" not "have a narrow quick escape".

4. No word in an idiom can be replaced by another word, e.g. "out of sight, out of mind" not "out of sight, out of heart".

5. The grammatical structures of an idiom cannot be changed. We have the idiom of "ring the bell" but "the bell was ringed" is not allowed (Baker, 1992:63).

Through the abovementioned definitions, it is concluded that idioms are important in every languages and due to the variety of cultures, sometimes there is no equivalent for a specific idiom in the target language. Moreover recognizing idioms is a really hard task for non-native speakers and translators need in-depth linguistic knowledge of the source text. Fernando (1996) suggests three ways of recognizing idioms:

1. That is a combination of words, for example red herring, make up, smell a rat, the coast is clear; however, even a word can be idiom, though there is a debate over this.

2. The idiom is something which is accepted and used although it first started as something new and on an ad hoc basis.

3. The meaning of an idiom cannot be obtained from its words. The above characteristics of an idiom are very general and can be used to identify not only idioms but also proverbs, similes, collocations, etc. (p.47).

\subsection{Colloquial Expressions}

Colloquial language mainly refers to informal or every day speeches like friendly talks or chatty or friendly speeches. Longman dictionary defines colloquial as "Language or words that are colloquial are used mainly in informal conversations rather than in writing or formal speeches." (Longman Dictionary of Contemporary English, Fifth Edition, 2005). The word colloquial is defined by American College Dictionary as quoted in McCrimmon (1963:169) "characteristic of or appropriate to ordinary or familiar conversation rather than formal speech or writing". He adds that this definition does not say that a colloquial word is wrong or undesirable, in fact it seems conversational (p.169). In continue he says that "a colloquialism is any word or expression which might appropriately be used in conversation among educated people". He also adds that colloquialism conveys popular words and idiomatic constructions (McCrimmon, 1963:169). Colloquial expressions also include constructions which are not strictly idioms, especially abbreviated or clipped forms of more formal words, such as ad for advertisement. An example of colloquial is provided here to clarify it more: to dig means to excavate, to break up or turn the soil with some instrument (Merriam-Webster, 1993:226). But the question "You dig it, man?" is colloquial and could be translated as "Do you like it?" or "Do you understand?" based on the situation.

Newmark (1988) suggests a stylistic scale of formality ranging from officialese to official, formal, neutral, informal, colloquial, slang and taboo (p. 14).

- Officialese: The consumption of any nutriments whatsoever is categorically prohibited in this establishment.

- Official: The consumption of nutriments is prohibited.

- Formal: You are requested not to consume food in this establishment.

- Neutral: Eating is not allowed here.

- Informal: Please don`t eat here.

- Colloquial: You can`t feed your face here.

- Slang: Lay off the nosh.

- Taboo: Lay off the fucking nosh.

Based on Newmark's (1988) stylistic scale colloquial language in definition lies between informal language and slang.

\section{Methodology}

\subsection{Corpus}

For the corpus of this study five famous American comedy animations were selected based on a purposive sampling technique (Dornyei, 2007:129). The main reason for selection of these animations was that they were famous comedy cartoons in English speaking countries and they had high rate in box office. They were also famous in non-English 
speaking countries even in Iran. Moreover, the target community of these animations was almost all ages from children to adult. The dubbed versions of these animations are available and the humorous expressions both cultural and linguistic can be found abundantly in them. The selected animated comedy movies are presented below.

- $\quad$ Ice Age 4

- $\quad$ Shrek 4

- Rio

- Kung Fu Panda

- $\quad$ Lion King 3

\subsection{Procedure}

The English movies were examined to identify idiomatic, colloquial and humorous expressions and then those expressions were compared with the Persian dubbed version. The researcher also assesses the quality of the translation strategies used in the dubs. For the analysis of the aforementioned corpora, the following classification of the moves was employed in order to describe and categorize the approaches and strategies of Persian translators when transferring such elements during dubbing. The function of humorous expressions is to produce laughter whereas; the primary function of idiomatic and colloquial expressions is not to produce laughter. This study claims that idiomatic and colloquial expressions are used to produce laughter in dubbing of comedy animations and as a result, they get a secondary function. The major moves in such rendition are categorized as in the following:

\section{Approaches to Humor}

- Humor translated to humor

- Humor translated to non-humor

- Non-humor translated to humor

2. Approaches to Idioms

- Idiom translated to idiom

- Idiom translated to non-idiom

- Non-idiom translated to idiom

3. Approaches to Colloquial Expressions

- Colloquial translated to colloquial

- Colloquial translated to non-colloquial

- Non-colloquial to colloquial

\section{Results}

The following are some examples selected from the five cartoons under study which are classified and analyzed based on the aforementioned taxonomy:

\subsection{Humorous Expressions Translated to Humorous Expressions}

Shrek: True love's kiss

Back translation: [visiting beloved]

Donkey: Hey, you have to take me to dinner first.

$$
\text { ميكُ اينطورى كه نحاه مى كنى يه طور اييه }
$$

Back translation: [Something is wrong with the way you are looking at me]

Shrek was reading the conditions of his contract with Rumple to find out a way to cancel it. It was true love's kiss which he read that aloud. Donkey misunderstood and thought that Shrek wanted to kiss him. Hence, he asked Shrek to take him to dinner first. The Donkey's sentence refers to a custom that when a boy meet a girl, he has to take her out before kissing. In Persian translation they changed the sentence since it is considered as taboo in Persian culture. However, it still retains the meaning. The English sentence is funny and the Persian translation is funny too.

\subsection{Humorous expressions Translated to Non-humorous expressions}

Shrek: Hey!

Back translation: [wait]

*Donkey: I'm being ass-napped!

*Donkey: Animal cruelty! Help 
Donkey used two funny expressions. First he said that he was being ass-napped instead of kidnapped and second he mentioned animal cruelty which are very funny in the original text. Yet, in Persian translation they deleted them because they were linguistically untranslatable. The English sentences are funny but their Persian translations are not.

\subsection{Non-humorous expressions Translated to Humorous expressions}

Blu: What kind of doctor are you?

$$
\text { اين انترنم نيست جهه برسه به دكتر }
$$

Back translation: [he is not an intern let alone a doctor]

The English sentence is not funny but its Persian translation is funny.

\subsection{Idiomatic expressions Translated to Idiomatic expressions}

Shrek: Do you know where Fiona is?

$$
\text { خره تو خبر دارى فيونا كجاست؟ }
$$

Back translation: [Donkey, do you have any idea where Fiona is?]

Donkey: Quiet ogre! You re goanna get me in trouble and I need this job. I am not going back to work for old McDonald.

هيس! ساكت! بر ام دردسر درست نكن. من اين شغلو احتياج دارم. عمراً ديخه برم دنبال خر حمالى، كار قبلى ام رو مى گم، كاركه نبود بى كارى بود

Back translation: [Hush up. Don`t make me any trouble. I need this job. I won`t work for old McDonald. My previous job, you know. That wasn`t a job, it was a waste of time]

Shrek being completely confused was captured in brougham by the witches and kept asking questions about whereabouts of the donkey and the donkey, who did not recognize him was frightened because if the witches heard them, he would lose his job. The funny thing here is that the donkey needs his job. The idiom old MacDonald that he used to refer to his previous job means to work hard with a low payment. In Persian translation they used a very funny idiom خر حمالىwhich means hard work with low payment like the work of the donkeys. The English sentence is an idiom and its Persian translation is an idiom too.

4.5 Idiomatic expressions Translated to Non-idiomatic expressions

Pedro: Yeah! I'm gonna pop that cage open like a soda can!

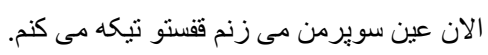

Back translation: [I'll smash your cage just like a Superman]

The English sentence is an idiom but its Persian translation is not.

4.6 Non-idiomatic expressions Translated to Idiomatic expressions

Shrek: Donkey, stop with the singing, will you?

Back translation: [Can you stop your cool song Donkey]

$$
\text { خره ميشه اون خر در جمنتو قطع كنى }
$$

Shrek woke up in the brougham and heard the donkey singing foolish things with a bad voice and asked him to stop that. In Persian, they have translated this sentence with a famous idiom which is usually used for people who sing with a bad voice. The English sentence is not an idiom but its Persian translation is.

\subsection{Colloquial expressions Translated to Colloquial expressions}

Granny: What are you peeping toms all looking at?

$$
\text { جش جرونا جشاتونو درويش كنين }
$$

Back translation: [Don`t ogle, you bastards]

Sid`s granny fell into the sea and Sid saved her. When Granny came out Diego and Manny were watching her and made her unpleasant. The English sentence is colloquial and so is its Persian translation.

\subsection{Colloquial expressions Translated to Non-colloquial expressions}

Another hyena: for your last meals, you're goanna eat those words.

$$
\text { بهتره ديگه وصيتتونو بكنين }
$$

Back translation: [it is time to make your will] 
The English sentence is colloquial while its Persian translation is not.

\subsection{Non-colloquial expressions Translated to Colloquial expressions}

Manny: you two were supposed to be responsible uncles!

$$
\text { دوخين بيينم- دنيا رو اب ببره شما اق دايى ها رو خواب مى بره }
$$

Back translation: [Move your ass. If the world is drawn by water you do not notice that]

Manny is jealous of his daughter. One day he woke up and could not find her, he asked the Possums, whom were considered as Peaches' uncle, to know where she was and why they did not watch her. The English sentence is not colloquial expression but its Persian translation is.

The findings of the study are presented in table 1.

Table 1. Data gathered from five animation comedies

\begin{tabular}{l|l|l}
\hline Category & Frequency & Percentage \\
\hline Humorous to humorous expressions & 5 & 6.8 \\
\hline Humorous to non-humorous expressions & 4 & 5.5 \\
\hline Non-humorous to humorous expressions & 11 & 15.3 \\
\hline Idiomatic to idiomatic & 7 & 9.7 \\
\hline Idiomatic to non-idiomatic & 3 & 4.2 \\
\hline Non-idiomatic to idiomatic & 20 & 27.8 \\
\hline Colloquial to Colloquial & 5 & 7 \\
\hline Colloquial to non-colloquial & 1 & 1.4 \\
\hline Non-colloquial to colloquial & 16 & 22.3 \\
\hline
\end{tabular}

Out of 20 instances of humorous expressions which were identified in the data, 4 of them did not transfer as humorous expressions in the TT; 5 humorous expressions were transferred successfully and 11 instances that were not humorous in the original text were transferred as humorous expressions in the dubbed Persian version. Translators had created 11 humorous expressions which did not exist in the original versions based on the visual elements and the context of the animations. Out of 30 instances of idiomatic expressions which were found in the data, 3 of them did not transfer as idiomatic expressions in the TT; 7 idiomatic expressions were transferred successfully as idiomatic expressions and 20 instances which were not idioms in the ST were rendered as idiom in the TT. Since the Persian language consists of a myriad of idioms, translators have rendered non-idiomatic expressions in the ST to idiomatic expressions in the TT, which makes the dubbed version funnier. Out of 22 instances of colloquial expression which were identified in the data, 5 colloquial expressions were transferred to colloquial expressions in the TT; 1 colloquial expression did not transfer as colloquial expression and 16 non-colloquial expressions in the ST were transferred as colloquial expressions in the TT. Needless to say that translation of non-colloquial expressions to colloquial expressions makes dubbed versions more hilarious.

\section{Discussion}

More specifically, the discussion is aimed at casting light on the micro strategies employed when translating humorous expressions from five comedy animations into Persian. The discussion will involve an analysis of the strategies and procedures employed in the translation process.

The results of the study verify that Persian translators tend to translate humorous expressions to humorous expressions, non-idiomatic to idiomatic expressions, non-colloquial to colloquial expressions. The results reveal that paraphrasing is a dominant translation strategy. Hence, it could be said that Persian translation is TT-oriented. To conclude, the Persian dubbed versions of movies in this investigation more or less focused conveying the effect of the ST rather than the form.

Some of the humorous elements did not transfer because they are culturally sensitive and the target audiences do not have sufficient background knowledge to understand them. Another important thing is that something which is considered humorous in one society may not necessarily be treated as such in another. The results of this research showed that culture- bound humorous expressions were generally deleted or substituted by other jokes and in some cases the humor was only partially transferred through literal translation.

The study could provide evidence that dubbed Persian versions seem to elicit more laughter from the audience which is because of the following:

a) The dubbed Persian versions use the resources of two languages for producing laughter. b) The dubbed Persian versions use idioms and colloquial expressions to give them another function, that is, to make children laugh. We know that the primary function of idioms and colloquial expressions is not to make people laugh, but in all these versions idiomatic and colloquial expressions have been used as a means to serve a secondary function; that is why the study 
included idioms and colloquial expressions in the examination of humorous expressions. c) The fact that there are 11 instances of non-humorous expressions translated to humorous expressions confirms that our translators were not simply translators. They collaborated with the writers to produce more laughter, making use of the resources of Persian as an additional source of humor. d) This is further confirmed by the fact that there are 20 instances of non-idiomatic expressions translated to idiomatic expression and 16 instances of non-colloquial expressions translated to colloquial expressions. The translators have used the idiomatic and colloquial resources of Persian mostly in cases where there are no idioms or colloquial expressions in the original. They actually used the second function of the idiomatic and colloquial expressions to produce humor.

In addition, based on the data gathered from translations of five cartoons, paraphrasing and literal translation were the most commonly used techniques in the dubbing of comedy animations from English to Persian. Referring to the suggested category for translation strategies of comedy animations, the following strategies are most frequently used in Persian dubbing translation: 1. Non-humorous expressions translated to humorous expressions 2. Non-idiomatic expressions translated to Idiomatic expressions 3. Non-colloquial expressions translated to colloquial expressions.

It is also apparent that Persian translators tend to create humorous expressions and translate non-humorous expressions to humorous expressions based on the context and the visual effects of the animations. This strategy perhaps has been used in response to the request of the clients since the addressee of these comedy animations were most children, and at the same time the final aim of these comedy animations were to make children laugh.

Also, a frequent technique which has been used by Persian translators was that they translate non-idiomatic expressions to idiomatic expressions. As discussed above the primary function of idioms is not to produce laughter but as the result displays Persian translators tend to translate non-idiomatic expressions to idiomatic expressions to elicit laughter. And this appeals more to audiences; moreover, translators can transfer the original message better and more clearly. Another scenario could be that this strategy also may has been used in favor of the client interests and as Persian translators had access to their rich language corpora with tons of idioms, it seemed so easy for them to find a suitable idiom which produce laughter in regard to the context and visual effects of the comedy animations.

Likewise, it is also evident that Persian translators tend to translate non-colloquial expressions to colloquial expressions. Although the primary function of colloquial expression is not to produce laughter, Persian translators used this strategy to elicit laughter and as a consequence they get secondary function. This creativity makes the dubbed versions funnier than the original versions especially with the use of different accents and jargons of Iranian.

\section{Conclusion}

As discussed before the goal of the present study is to compare and analyze translation techniques adopted by Persian translators in the dubbing of comedy animations. The findings of the study show that translators recognized humor elements and domesticated them in translating into Persian. In fact, it was not only a translation but also a cross-cultural transfer from English to Persian. Humor translation in dubbing is subject to numerous factors. Translators must pay attention to constraints of dubbing such as synchronization and time limitation. In order to achieve a successful dubbed product, translators have to create the same impression as the original movie. To do this task, they need to localize some elements. Translation shifts are usually involved in humor transfer due to various difficulties connected with it. Shifts of meaning in humor translation are not regarded negative as long as they result in achieving the same humorous effect as the source text does. During the paper a revelation is that humor investigation has been done seriously at academic level in recent years. But it is apparent that it is not sufficient and further research is needed in this field. In brief, based on the result, and of course in the light of the limitations of the study, such as relatively small corpus, the following points can be concluded. a) Persian translators seem to be target oriented and tend to localize the sentences and use familiar expressions. b) Persian translators appear to tend to transfer non-humor elements to humor elements based on the visual context of the animation. c) Persian translators seem to tend to translate non-idiomatic sentences to idiomatic ones. d) And, taboo language is prone to be deleted in Persian dubbed comedy animated movies probably due to the cultural restraints invested in the Iranian culture.

\section{References}

Akmali, F. (2012). Loss and Gain in Humor Translation: A Case Study of the Ethics of the Aristocrats http://proz.com/translation-articles/articles/3488

Baker, M. (1992). In Other Words: A Coursebook On Translation. London: Routledge.

Chiaro, D. (Ed.). (2009b). Issues in Audiovisual Translation. London: Routledge.

Delabastita, D. (1989). Translation and Mass-communication: Film and TV Translation as Evidence of Cultural Dynamics. Bable, 35(4), 193-218.

Dornyei, Z. (2007). Research Methods in Applied Linguistics. New York: Oxford.

Ferrnando, C. (1996). Idioms and Idiomaticity. London: Oxford University Press.

Gottlieb, H. (1997c). Subtitles, Translation and Idioms. (PhD), University of Copenhagen, Copenhagen.

Langacher, W. R. (1968). Language and its Structure: some fundamental linguistic concepts. New York: Harcourt, Brace and world. 
Longman. (Ed.) (2005) (4 ed.). London: Pearson Education Limited.

Luyken, G. M., Herbst, T., Langham-Brown, J., Reid, H., \& Spinhof, H. (1991). Overcoming Language Barriers in Television: Dubbing and Subtitling for the European Audience. Manchester: European Institue for the Media.

McCrimmon, J. (1963). Writting With a Purpose New York: Houghton.

Merriam-Webster, I. (Ed.) (1993) (3 ed.). Springfield: Inc Lexicon Publications.

Munday, J. (2008). Introducing Translation Studies: Theories and Applications (2 Ed.). London \& New York: Routledge.

Newmark, P. (1988). A Textbook Of Translation. London: Prentice Hall.

Orero, P. (2004). Topics in Audiovisual Translation. Chapel Hill: John Benjamins.

Ross, A. (1998). The Language of Humor. New York: Routledge

Vandaele, J. (2002). Introduction: Reconstructing Humor: Meaning and Means. Special Issue of Translator, 8(2), 149172.

Williams, \& Chesterman. (2002). The Map: A Beginer`s Guide to Doing Research in Translation Studies. Manchester: St.Jerome. 